\title{
ANALISIS STATUS DAN INDIKATOR KINERJA PEMBANGUNAN BERKELANJUTAN PERIKANAN MINI PURSE SEINE DI PANTAI UTARA JAWA
}

Tjahjo Tri Hartono*), M. Ali Iqbal"), Sonny Koeshendrajana"), A. Azizi") dan Taryono")

\begin{abstract}
ABSTRAK
Hingga saat ini informasi dasar bagi formulasi kebijakan pembangunan berkelanjutan di subsektor perikanan tangkap di Indonesia masih banyak didasarkan pada hasil pengkajian stok sumberdaya (stock assessment) species target. Pendekatan stock assessment ini sangat membutuhkan informasi yang substansial, survei independen dan model yang rumit serta banyak dinilai tidak cukup memadai untuk menilai kelestarian sumberdaya perikanan yang sangat bersifat multi-dimensi. Oleh karena itu penelitian ini mencoba menggunakan pendekatan lain berupa metode Rapid Appraisal for Fisheries (RAPFISH). RAPFISH adalah suatu metode atau pendekatan berbasis statistik multidimensional scaling (MDS), yang berdasarkan hasil penelitian di beberapa negara telah diketahui dengan cepat, mudah dan akurat mampu mengukur secara multi-dimensi status keberlanjutan perikanan tangkap. Kegiatan penelitian yang telah dilakukan sepanjang bulan Mei hingga November 2003 di Kabupaten Indramayu, Tuban dan Lamongan serta Kota Pekalongan dipusatkan pada kajian status keberlanjutan perikanan mini purse seine di Pantai Utara Jawa. Pemilihan lokasi dan jenis perikanan tangkap ini dilandasi pada status over exploited baik berdasarkan wilayah perairan maupun kelompok ikan pelagis kecil sebagai ikan target dari perikanan tangkap yang memerlukan penanganan serius dan sesegera mungkin. Hasil analisis ordinasi RAPFISH menunjukkan status keberlanjutan perikanan mini purse seine di keempat lokasi penelitian relatif sama. Perbaikan status keberlanjutan perikanan mini purse seine di Pantai Utara Jawa dapat dilakukan melalui peningkatan kinerja beberapa atribut yang berdasarkan hasil analisis leverage di dalam metode RAPFISH terindikasi berpengaruh besar didalam menentukan status keberlanjutan perikanan tangkap tersebut.
\end{abstract}

ABSTRACT: The analysis of status and performance indicators of sustainable development of mini purse seine fisheries in North Coast of Java. By: Tjahjo Tri Hartono, Sonny Koeshendrajana, M. Ali Iqbal and Taryono

At present, the basic information needed to build the sustainable development guidance in capture fisheries in Indonesia is heavily based on the result of stock assessment of targeted species. This assessment requires substansial information, independent survey and complicated model. Besides that the stock assessment study known inappropriate to assess the sustainability of fishery resources since the fishery resources has a multidimensional characteristic. Therefore, an alternative approached was applied by using Rapid Appraisal for Fisheries (RAPFISH) method. This approach is based on multidimensional scaling analysis which is known as a swiftly and easily method and also quite accurate to measure multidimensional sustainability status of capture fishery as it had been applied in some states. The research had been conducted from May to November 2003 and was located in Indramayu, Pekalongan, Tuban and Lamongan regencies. The research focused on assessment of sustainability status of mini purse seine that operates in northem coast of Java. Selection of fishery and locations based on over exploited status, both territorial water region (Java Sea) and small pelagic fish group as target fish of mini purse seine fishery by which needs a serious action as soon as possible. The results of RAPFISH ordination show that sustainability status of mini purse seine in all research locations relatively similar. Leverage analysis indicates that sustainability status of mini purse seine in north coast of Java could be improved through increasing the performance of several attributes that have a high influence to the sustainability status of the fishery.

KEYWORDS: $\quad$ sustainable development, RAPFISH, mini purse seine fishery, north coast of java

Peneliti pada Pusat Riset Pengolahan Produk dan Sosial Ekonomi Kelautan dan Perikanan

Pengajar pada Departemen Sosial Ekonomi Perikanan dan Kelautan, Fakultas Perikanan dan IImu Kelautan, IPB 


\section{PENDAHULUAN}

Pembangunan sektor kelautan dan perikanan merupakan isu penting di Indonesia. Hal ini timbul semenjak disadari bahwa: (1) Indonesia dengan luas wilayah laut 5,8 juta $\mathrm{km}^{2}, 17.508$ pulau dan garis pantai sejauh $81.000 \mathrm{~km}$ merupakan suatu negara dengan potensi sumberdaya kelautan dan perikanan yang begitu besar; (2) Menipisnya sumberdaya di daratan mengakibatkan sumberdaya kelautan menjadi tumpuan harapan pembangunan nasional di masa depan; (3) Pergeseran poros perekonomian global dari Eropa Atlantik menjadi Asia Pasifik yang mengakibatkan sumberdaya kelautan yang dimiliki Indonesia merupakan keunggulan komparatif yang harus dimanfaatkan secara optimal; dan (4) Wilayah pesisir dan lautan merupakan prioritas utama untuk pengembangan berbagai kegiatan ekonomi (Dahuri et al., 1996).

Mengacu pada keempat hal tersebut, pada tahun 2000 pemerintah membentuk Departemen Kelautan dan Perikanan (DKP). Departemen ini bertugas dan berwenang di dalam menangani pembangunan sektor kelautan dan perikanan. Tugas dan wewenang tersebut kemudian dilakukan melalui berbagai arahan kebijakan pembangunan sektor kelautan dan perikanan yang telah dikeluarkan dan dilaksanakan hingga saat ini. Namun demikian, hingga saat ini arahan kebijakan pembangunan tersebut masih memerlukan berbagai bahan dan informasi yang dapat mendukung terwujudnya suatu pembangunan kelautan dan perikanan yang berkelanjutan. Selama ini sumber bahan dan informasi tersebut salah satunya adalah dari hasil kegiatan penelitian. Terkait dengan permasalahan yang telah dikemukakan, diperlukan penelitian yang dapat menilai status keberlanjutan pengelolaan sumberdaya kelautan dan perikanan secara cepat dan tepat. Diharapkan hasil yang diperoleh dapat menjadi bahan bagi arahan kebijakan yang secara cepat dapat tersedia dan dapat terjamin akurasinya

Permasalahan yang dihadapi dalam pembangunan kelautan dan perikanan yang berkelanjutan adalah pendekatan atau penelitian penilaian kelestarian sumberdaya hayati perikanan tangkap masih lebih banyak dilakukan dengan pengkajian stok sumberdaya (stock assessment) species target. Pendekatan ini lebih memiliki penekanan pada aspek biologis atau ekologis sumberdaya hayati laut. Konsekuensi dari pendekatan ini sangat memerlukan informasi yang substansial, survei independen dan model yang rumit. Kesemua prasyarat tersebut merupakan kendala bagi negara-negara berkembang seperti Indonesia (Alder et al., 2002). Kendala lain adalah tidak cukup memadainya hasil kajian yang diperoleh untuk menilai kelestarian sumberdaya perikanan yang sangat bersifat multi-dimensi.

Multidimensi pengelolaan sumberdaya perikanan terkait dengan bio-ekologis species target (ikan) dan habitatnya. Di sisi lain juga terkait dengan sistem sosial-ekonomi masyarakat nelayan, jenis dan tingkat teknologi dalam mengeksploitasi sumberdaya kelautan dan perikanan. Pengelolaan sumberdaya perikanan juga perlu memperhatikan berbagai peraturan dan pengaturan formal dan informal yang terkait dengan pengelolaan sumberdaya perikanan tangkap

Atas dasar fakta-fakta tersebut maka metode Rapid Appraisal for Fisheries (RAPFISH), suatu metode atau pendekatan berbasis statistik multidimensional scaling (MDS) diadopsi untuk mengukur status keberlanjutan (sustainability status) perikanan tangkap yang lebih sesuai dan menggambarkan kondisi perikanan tangkap di Indonesia. Metode ini mulai dikembangkan oleh RAPFISH Group, Fisheries Center, University of Columbia sejak tahun 1999.

Kegiatan penelitian dipusatkan pada kegiatan pengkajian status kelestarian sumberdaya perikanan tangkap mini purse seine (MPS) di Pantai Utara Jawa. Pemilihan lokasi dan jenis perikanan dilandasi pada hasil beberapa kajian sebelumnya yang mengindikasikan status over exploited, baik berdasarkan wilayah perairan maupun kelompok ikan pelagis kecil sebagai ikan target (Taryono, 2003).

Penelitian ini memiliki tujuan: (a) Mengetahui gambaran tentang status keberlanjutan sumberdaya perikanan tangkap berdasarkan alat tangkap MPS di Pantai Utara Jawa; (b) Menentukan dan menyusun indikator kinerja pembangunan berkelanjutan perikanan tangkap MPS di lokasi wilayah pengelolaan terpilih; dan (c) Merumuskan rekomendasi kebijakan dalam rangka perbaikan atau peningkatan status keberlanjutan perikanan tangkap di Pantai Utara Jawa dan di tempat lainnya yang memiliki permasalahan serupa

\section{METODE}

\section{Data dan Sumber Data}

Data yang dikumpulkan terdiri atas data sekunder dan data primer. Data sekunder merupakan titik awal penilaian kinerja pembangunan perikanan tangkap yang menjadi tujuan penelitian. Data sekunder yang dikumpulkan berupa statistik perikanan tangkap, laporan tahunan dinas, statistik tahunan daerah maupun laporan penelitian yang telah terdokumentasi. Data sekunder didapat dari beberapa instansi seperti Departemen Kelautan dan Perikanan, Dinas Kelautan 
dan Perikanan Tingkat Propinsi/Kabupaten/Kota, Badan Pusat Statistik Tingkat Propinsi/Kabupaten/ Kota, dan instansi lainnya yang terkait.

Informasi yang belum diperoleh dari data sekunder, dilengkapi sebagai data primer. Pengumpulan data primer dilakukan melalui wawancara langsung dengan para informan. Informan adalah para pemangku kepentingan perikanan di lokasi penelitian (Tabel 1).

\section{Teknik Pengumpulan Data}

Pengumpulan data menggunakan instrumen dalam bentuk kuesioner. Kuesioner ini berfungsi sebagai pedoman tanya jawab bagi pelaksana survei. Pada dasarnya kuesioner yang digunakan mengacu pada kuesioner kegiatan Penelitian Indikator Kinerja Sektor Kelautan dan Perikanan, tahun 2002. Kuesioner kegiatan penelitian tersebut dibuat berdasarkan lima dimensi yang akan dianalisis di dalam RAPFISH, dimana dimensi maupun atribut yang digunakan mengacu pada Code of Conduct for Responsible Fisheries (FAO, 1999). Dalam penelitian ini dimensi dan atribut yang telah ada sebelumnya dimodifikasi berdasarkan hasil diskusi antar pakar perikanan saat sebelum kegiatan verifikasi lapang dilakukan (Tabel 2). Modifikasi kuesioner dilakukan dengan tujuan mendapatkan dimensi-dimensi dengan atributatributnya yang dapat dijadikan acuan bagi penetapan status keberlanjutan perikanan tangkap di Indonesia.

\section{Metode Pengolahan dan Analisis Data}

Pengolahan data dilakukan dengan teknik ordinasi (menempatkan sesuatu pada urutan atribut yang terukur), yang kemudian dianalisis dengan menggunakan teknik Multi-Dimensional Scaling (MDS). Teknik MDS ini pada dasarnya adalah suatu teknik analisis statistik yang mencoba melakukan transformasi multidimensi ke dalam dimensi yang lebih rendah. Analisis MDS yang dilakukan mengacu

Tabel 1. Informan penelitian status pembangunan bekelanjutan perikanan MPS di Pantai Utara Jawa, 2003 Table 1. Informan of sustainable development of MPS fisheries in North Coast of Java, 2003

\begin{tabular}{|c|c|c|c|}
\hline No. & $\begin{array}{l}\text { Informan/ } \\
\text { Informan }\end{array}$ & $\begin{array}{c}\text { Teknik } \\
\text { Pengambilan Contoh/ } \\
\text { Sampling Method }\end{array}$ & $\begin{array}{l}\text { Keterangan/ } \\
\text { Note }\end{array}$ \\
\hline 1. & $\begin{array}{l}\text { Kepala Dinas Perikanan } \\
\text { Daerah Tingkat Propinsi/ } \\
\text { Kabupaten/ Kota } \\
\text { Head of Fisheries Agency at } \\
\text { Province and Regency }\end{array}$ & $\begin{array}{l}\text { Purposif/ } \\
\text { Purposive }\end{array}$ & \multirow{2}{*}{$\begin{array}{l}\text { Bila tidak dapat diakses, dilakukan } \\
\text { dengan pejabat yang mewakili dan } \\
\text { kompeten/ } \\
\text { If the head of fisheries agency } \\
\text { cannot be accessed, then the } \\
\text {-information will be conducted from } \\
\text { other officer representative. }\end{array}$} \\
\hline 2. & $\begin{array}{l}\text { Kepala TPI, KUD/ } \\
\text { Head of Fish Landing, KUD }\end{array}$ & $\begin{array}{l}\text { Purposif/ } \\
\text { Purposive }\end{array}$ & \\
\hline 3 & $\begin{array}{l}\text { Tokoh nelayanl } \\
\text { Fishers figures }\end{array}$ & $\begin{array}{l}\text { Purposifl } \\
\text { Purposive }\end{array}$ & \\
\hline 4. & $\begin{array}{l}\text { Nelayan mini purse seinel } \\
\text { Mini purse seine fishers }\end{array}$ & $\begin{array}{l}\text { Purposif/ } \\
\text { Purposive }\end{array}$ & $\begin{array}{l}\text { Kapal MPS lebih kurang adalah } \\
\text { kapal kayu dengan panjang } \pm 12- \\
17 \mathrm{~m} \text {, bobot < } 30 \mathrm{GT} \text {, mesin } \\
\text { outboard, panjang jaring } 200-300 \\
\mathrm{~m} \text { dengan kedalaman } 40-60 \mathrm{~m} \\
\text { serta ukuran mata jaring kantong } 3 / 4 \\
\text { inci/ MPS boat is a wooden ship } \\
\text { which has } \pm 12-17 \mathrm{~m} \text { lenght, }<30 \\
\mathrm{GT} \text {, outboard machine, } 200-300 \\
\text { lenght and } 40-60 \text { widht of net and } \\
3 / 4 \text { inches size of mesh size sack. }\end{array}$ \\
\hline
\end{tabular}


Tabel 2. Modifikasi dimensi dan atribut RAPFISH yang digunakan dalam penelitian pembangunan berkelanjutan perikanan MPS di Pantai Utara Jawa, 2003

Table 2. Modified dimensions and attributes of RAPFISH on sustainable development of mps fisheries in North Coast of Java, 2003

\begin{tabular}{|c|c|c|c|c|}
\hline \multicolumn{5}{|c|}{ Dimensi/Dimensions } \\
\hline $\begin{array}{l}\text { Ekologi/ } \\
\text { Ecology }\end{array}$ & $\begin{array}{l}\text { Ekonomi/ } \\
\text { Economic }\end{array}$ & $\begin{array}{l}\text { Sosiall } \\
\text { Social }\end{array}$ & $\begin{array}{l}\text { Teknologi/ } \\
\text { Technology }\end{array}$ & $\begin{array}{l}\text { Pengaturan/ } \\
\text { Governance }\end{array}$ \\
\hline Exploitation status* & Profitability $^{*}$ & $\begin{array}{l}\text { Socialization of } \\
\text { fishing }\end{array}$ & Trip lenght & Altematives \\
\hline Recruitment variability & $\begin{array}{l}\text { Fisheries in } \\
\text { GDP }\end{array}$ & $\begin{array}{l}\text { New entrants } \\
\text { into fishery }\end{array}$ & Landing sites & $\begin{array}{l}\text { Equity in entry } \\
\text { to fishery }\end{array}$ \\
\hline Change in trophic level & Average wage & Fishing sector & $\begin{array}{l}\text { Onboard } \\
\text { handling }\end{array}$ & $\begin{array}{l}\text { Just } \\
\text { management }\end{array}$ \\
\hline Migratory range & Other income & $\begin{array}{l}\text { Environmental } \\
\text { knowledge }\end{array}$ & $\begin{array}{l}\text { Pre-sale } \\
\text { processing }\end{array}$ & $\begin{array}{l}\text { Mitigation of } \\
\text { habitat } \\
\text { destruction }\end{array}$ \\
\hline Range collapse* & $\begin{array}{l}\text { Sector } \\
\text { employment }\end{array}$ & Education level & Gear & $\begin{array}{l}\text { Mitigation of } \\
\text { ecosystem } \\
\text { depletion }\end{array}$ \\
\hline Size of fish caught & $\begin{array}{l}\text { Ownership } \\
\text { transfer }\end{array}$ & Conflict status & Selective gear & Illegal fishing \\
\hline Catch before maturity & Market & Fisher influence & FADS & $\begin{array}{l}\text { Discards and } \\
\text { wastes }\end{array}$ \\
\hline $\begin{array}{l}\text { Discarded bycatch } \\
\text { Primary production }\end{array}$ & Subsidy* & $\begin{array}{l}\text { Fishing income } \\
\text { Kin participation }\end{array}$ & $\begin{array}{l}\text { Vessel size } \\
\text { Catching } \\
\text { power }\end{array}$ & $\begin{array}{l}\text { Limited entry } \\
\text { Marketable } \\
\text { right }\end{array}$ \\
\hline Exploitation status* & & $\begin{array}{l}\text { Adjacency and } \\
\text { reliance } \\
\text { Influences of } \\
\text { ethical formation }\end{array}$ & $\begin{array}{l}\text { Gear side } \\
\text { effect }\end{array}$ & $\begin{array}{l}\text { Number of } \\
\text { coastal } \\
\text { regulation } \\
\text { Conflicting } \\
\text { regulation } \\
\text { Law } \\
\text { enforcement }\end{array}$ \\
\hline
\end{tabular}

Sumber /Source: Pitcher \& Preikshot (2001)

pada metoda RAPFISH (Rapid Appraisal for Fisheries), suatu metode untuk mengevaluasi keberlanjutan perikanan secara multidissipliner yang dikembangkan sejak tahun 1999 (Pitcher \& Preikshot, 2001).

Secara garis besar, analisis MDS dalam metoda RAPFISH mencakup kegiatan-kegiatan sebagaimana tercantum pada Gambar 1. Pada tahap awal, dua hal yang perlu dilakukan adalah: pertama, 'pendefinisian perikanan' atau penentuan perikanan yang akan dianalisis, dikaji, diukur kinerjanya. Kegiatan ini mencakup pemberian definisi perikanan berdasarkan cakupan wilayahnya, yang diwakili oleh alat tangkap tertentu. Penelitian ini memilih untuk mengkaji mini purse seine di Pantai Utara Jawa. Kegiatan kedua, pengkajian indikator berupa proses pencirian setiap indikator berdasarkan informasi yang mendukung. Informasi dikumpulkan melalui studi literatur maupun melalui berbagai cara pengumpulan data primer. Sehingga dapat disimak bahwa pelaksanaan dua kegiatan ini adalah sebagai bagian dari tahap pengumpulan data. 
Langkah selanjutnya adalah tahapan 'skoring' Dalam tahap ini data yang dikumpulkan, baik melalui studi literatur maupun melalui kegiatan lapang, ditransformasikan ke dalam satuan kuantitatif atau skor, dengan besaran nilai atau skor tersebut didasari pada skor yang tertera pada panduan RAPFISH (Pitcher \& Preikshot, 2001). Pemberian skor kemudian dilanjutkan dengan Analisis Ordinasi Multidimensional Scaling (MDS). Analisis ini bertujuan melakukan posisi relatif dari perikanan terhadap ordinari buruk sampai baik (skala 0\% hingga 100\%). Dengan kata lain, semakin mendekati nilai $0 \%$ berarti semakin rendah kinerja keberlanjutan dari setiap dimensi yang dianalisis, sebaliknya semakin mendekati ke arah nilai $100 \%$ menandakan dimensi yang dianalisis semakin baik kinerja keberlanjutannya.

Disamping analisis ordinasi, dilakukan pula analisis Monte Carlo. Analisis ini dilakukan untuk menentukan aspek ketidak-pastian dan anomali dari atribut yang dianalisis. Sedangkan analisis Leverage sebagai analisis lain yang juga dilakukan untuk mengetahui tingkat sensitifitas setiap atribut masing-masing dimensi yang dianalisis.
Berdasarkan hasil-hasil tersebut di atas, langkah terakhir dari analisis RAPFISH adalah analisis keberlanjutan. Di dalam tahap analisis ini, dilakukan kajian terhadap dimensi-dimensi yang perlu mendapatkan perhatian dalam upaya mengusahakan keberlanjutannya.

\section{HASIL DAN BAHASAN}

\section{Keberlanjutan Perikanan Tangkap Mini Purse Seine (MPS)}

Hasil penelusuran data sekunder di berbagai laporan ataupun studi yang telah terdokumentasi, disertai dengan kegiatan verifikasi lapang atau pengumpulan data primer di keempat wilayah pengelolaan perikanan tangkap menghasilkan skor bagi setiap atribut (total 50 atribut) untuk kelima dimensi yang dianalisis (Tabel 3 ).

Pada perikanan tangkap MPS Kabupaten Lamongan diketahui skor kedua atribut "killer" dimensi ekologi, yaitu exploitation status $(3,0)$ dan range collapse $(3,0)$ secara total adalah enam $(6,0)$. Metoda

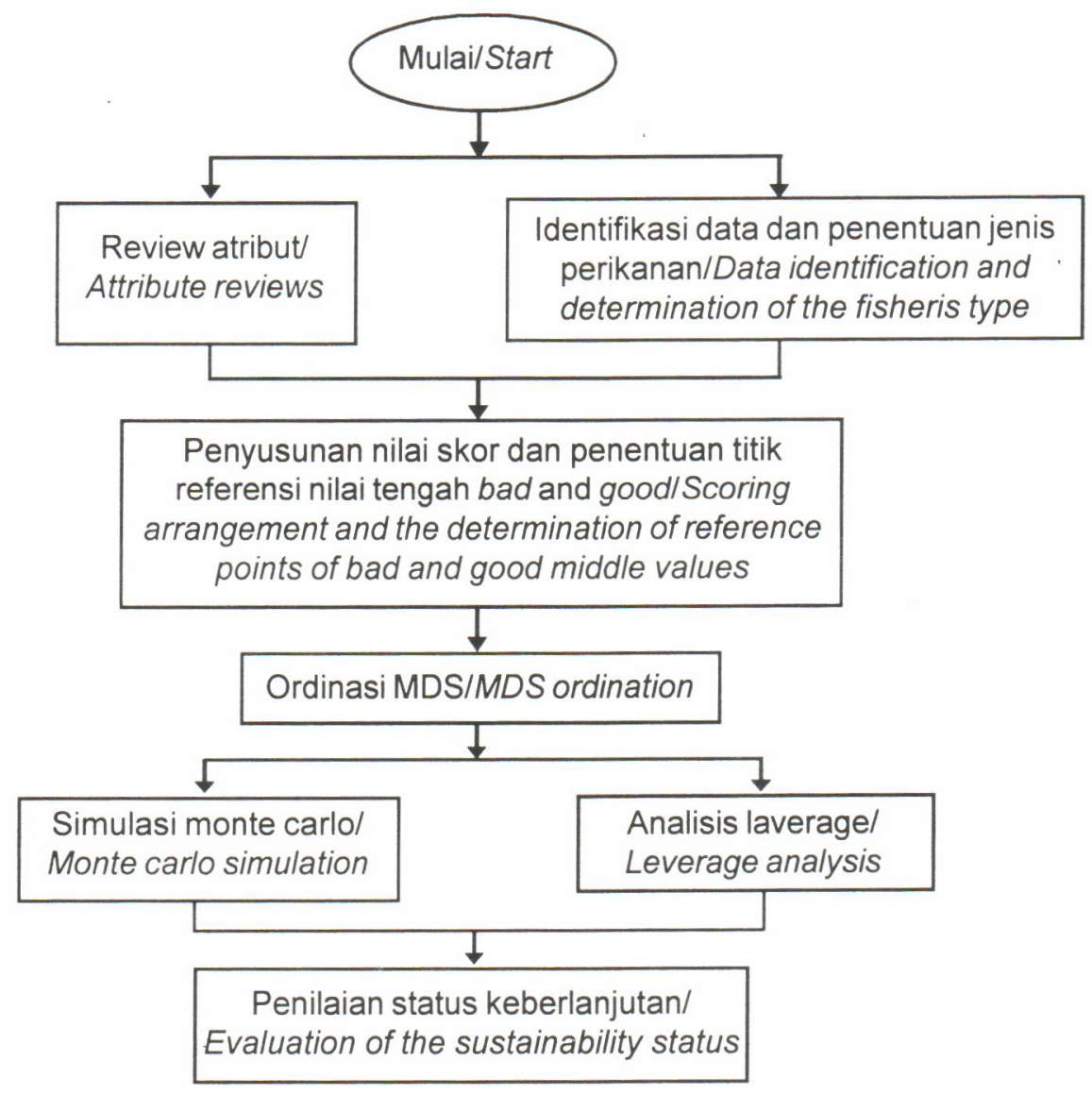

Gambar 1. Tahapan analisis aplikasi MDS dalam teknik RAPFISH (Taryono, 2003)

Figure 1. Stage of analysis of the MDS application on RAPFISH (Taryono, 2003) 
Tabel 3. Rekapitulasi skor atribut status keberlanjutan perikanan MPS Pantai Utara Jawa (Hasil analisis ordinasi MDS), 2003

Table 3. Score recapitulation of sustainability status attributes of MPS fishery of North Coast Java (Analysis MDS ordination results), 2003

\begin{tabular}{|c|c|c|c|c|c|c|c|}
\hline \multirow[t]{2}{*}{$\begin{array}{c}\text { Dimensi/ } \\
\text { Dimensions }\end{array}$} & \multirow[t]{2}{*}{$\begin{array}{l}\text { Atribut/ } \\
\text { Attributes }\end{array}$} & \multicolumn{2}{|c|}{$\begin{array}{c}\text { Skala Skor Status } \\
\text { Keberlanjutan/ } \\
\text { The Scale of } \\
\text { Sustainable } \\
\text { Status Score } \\
\end{array}$} & \multicolumn{4}{|c|}{$\begin{array}{l}\text { Nilai Skor Keberlanjutan } \\
\text { per Lokasi Penelitian/ } \\
\text { Value of Sustainable Score } \\
\text { for Each Regency }\end{array}$} \\
\hline & & $\begin{array}{l}\text { Baik/ } \\
\text { Good } \\
\end{array}$ & $\begin{array}{c}\text { Buruk/ } \\
\text { Bad }\end{array}$ & IND & PKL & TBN & LMG \\
\hline \multirow{9}{*}{$\begin{array}{l}\text { Ekologil } \\
\text { Ecology }\end{array}$} & Exploitation status ${ }^{*}$ & 0 & 4 & 3 & 3 & 3 & 3 \\
\hline & Recruitment variability & 0 & 2 & 1 & 1 & 1 & 1 \\
\hline & Change in trophic level & 0 & 2 & 1 & 1 & 1 & 2 \\
\hline & Migratory range & 0 & 2 & 1 & 1 & 1 & 1 \\
\hline & Range collapse* & 0 & 3 & 2 & 1 & 2 & 3 \\
\hline & Size of fish caught & 0 & 3 & 1 & 1 & 1 & 2 \\
\hline & Catch before maturity & 0 & 2 & 1 & 0.5 & 1 & 1 \\
\hline & Discarded by catch & 0 & 2 & 0 & 0 & 0 & 0 \\
\hline & Primary production & 3 & 0 & 3 & 3 & 3 & 3 \\
\hline \multirow{8}{*}{$\begin{array}{l}\text { Ekonomil } \\
\text { Economic }\end{array}$} & Profitability ${ }^{*}$ & 3 & 0 & 1 & 1 & 2 & 3 \\
\hline & Fisheries in GDP & 2 & 0 & 0 & 0 & 0 & 0 \\
\hline & Average wage & 4 & 0 & 3 & 2 & 2 & 2 \\
\hline & Other income & 0 & 3 & 3 & 3 & 3 & 3 \\
\hline & Sector employment & 0 & 2 & 0 & 0 & 0 & 0 \\
\hline & Ownership transfer & 0 & 2 & 1 & 1 & 1 & 1 \\
\hline & Market & 0 & 2 & 0 & 0 & 0 & 0 \\
\hline & Subsidy* & 0 & 4 & 1 & 1 & 1. & 1 \\
\hline \multirow{11}{*}{$\begin{array}{l}\text { Sosial/ } \\
\text { Social }\end{array}$} & Socialization of fishing & 2 & 0 & 1 & 1 & 1 & 1 \\
\hline & New entrants into fishery & 0 & 3 & 0 & 0 & 0 & 0 \\
\hline & Fishing sector & 0 & 2 & 0 & 0 & 0 & 0 \\
\hline & Environmental knowedge & 2 & 0 & 1 & 1 & 1 & 1 \\
\hline & Education level & 2 & 0 & 2 & 1 & 1 & 2 \\
\hline & Conflict status & 0 & 2 & 0 & 0 & 0 & 0 \\
\hline & Fisher influence & 2 & 0 & 1 & 1 & 0.5 & 0.5 \\
\hline & Fishing income & 2 & 0 & 2 & 1 & 2 & 2 \\
\hline & Kin participation & 4 & 0 & 4 & 0 & 1 & 2 \\
\hline & Adjacency and reliance & 3 & 0 & 2 & 2 & 3 & 3 \\
\hline & Influences of ethical formation. & 4 & 0 & 2 & 2 & 2 & 2 \\
\hline \multirow{10}{*}{$\begin{array}{l}\text { Teknologi/ } \\
\text { Technology }\end{array}$} & Trip lenght & 0 & 4 & 2 & 2 & 2 & 2 \\
\hline & Landing sites & 0 & 3 & 2 & 2 & 0 & 1.5 \\
\hline & Onboard handling & 3 & 0 & 2 & 2 & 2 & 2 \\
\hline & Pre-sale processing & 2 & 0 & 1 & 1 & 0.5 & 0.5 \\
\hline & Gear & 0 & 1 & 1 & 1 & 1 & 1 \\
\hline & Selective gear & 2 & 0 & 0.5 & 0.5 & 0.5 & 0.5 \\
\hline & FADS & 0 & 1 & 0 & 0 & 0 & 0 \\
\hline & Vessel size & 0 & 4 & 1 & 1 & 1 & 1 \\
\hline & Catching power & 0 & 4 & 2 & 2 & 2 & 2 \\
\hline & Gear side effect & 0 & 2 & 0 & 0 & 0 & 0 \\
\hline
\end{tabular}


Tabel 3. Rekapitulasi skor atribut status keberlanjutan perikanan MPS Pantai Utara Jawa (Hasil analisis ordinasi MDS), 2003 (lanjutan)

Table 3. Score recapitulation of sustainability status attributes of MPS fishery of North Coast Java (Analysis MDS ordination results), 2003 (continued)

\begin{tabular}{|c|c|c|c|c|c|c|c|}
\hline \multirow[t]{2}{*}{$\begin{array}{c}\text { Dimensil } \\
\text { Dimensions }\end{array}$} & \multirow[t]{2}{*}{$\begin{array}{c}\text { Atribut/ } \\
\text { Attributes }\end{array}$} & \multicolumn{2}{|c|}{$\begin{array}{c}\text { Skala Skor Status } \\
\text { Keberlanjutanl } \\
\text { The Scale of } \\
\text { Sustainable } \\
\text { Status Score }\end{array}$} & \multicolumn{4}{|c|}{$\begin{array}{c}\text { Nilai Skor Keberlanjutan } \\
\text { per Lokasi PenelitianI } \\
\text { Value of Sustainable Score } \\
\text { for Each Regency }\end{array}$} \\
\hline & & $\begin{array}{l}\text { Baik/ } \\
\text { Good }\end{array}$ & $\begin{array}{c}\text { Buruk/ } \\
\text { Bad }\end{array}$ & IND & PKL & TBN & LMG \\
\hline Pengaturan/ & Alternatives & 2 & 0 & 0 & 0 & 0 & 0 \\
\hline \multirow[t]{11}{*}{ Governance } & Equity in entry to fishery & 2 & 0 & 0 & 1 & 1 & 0 \\
\hline & Just management & 4 & 0 & 0 & 1 & 0 & 0 \\
\hline & Mitigation of habitat destruction & 4 & 0 & 1 & 1 & 0.5 & 0.5 \\
\hline & Mitigation of ecosystem depletion & 4 & 0 & 3 & 3 & 3 & 3 \\
\hline & Illegal fishing & 0 & 2 & 3 & 3 & 3 & 3 \\
\hline & Discards and wastes & 0 & 2 & 0 & 0 & 0 & 0 \\
\hline & Limited entry & 4 & 0 & 0 & 0 & 0 & 0 \\
\hline & Marketable right & 2 & 0 & 0 & 0 & 0 & 0 \\
\hline & Number of coastal regulation & 2 & 0 & 2 & 2 & 2 & 2 \\
\hline & Conflicting regulation & 0 & 1 & 2 & 2 & 2 & 2 \\
\hline & Law enforcement & 2 & 0 & 1 & 1 & 1 & 1 \\
\hline
\end{tabular}

Keterangan/Remark: * = Atribut "killer"

IND = Perikanan Tangkap MPS Kab. Indramayu/Capture Fisheries MPS in Indramayu Regency

PKL = Perikanan Tangkap MPS Kota Pekalongan/Capture Fisheries MPS in Pekalongan Regency

TBN = Perikanan Tangkap MPS Kab. Tuban/Capture Fisheries MPS in Tuban Regency

LMG = Perikanan Tangkap MPS Kab. Lamongan/Capture Fisheries MPS in Lamongan Regency

RAPFISH menyatakan bahwa apabila nilai kedua atribut "killer" dimensi ekologi suatu perikanan yang dianalisis lebih dari lima, maka secara keseluruhan status keberlanjutan perikanan tersebut, dalam hal ini perikanan tangkap MPS di Kabupaten Lamongan, dari sisi dimensi ekologi sudah buruk.

Hasil analisis ordinasi multidimensional scaling (MDS) terhadap skor setiap atribut dari kelima dimensi yang dianalisis memberikan gambaran mengenai kondisi atau status kelestarian perikanan tangkap di keempat lokasi penelitian. Hasil analisis ordinasi MDS tersebut secara rinci tersaji pada Tabel 4.

Nilai ordinasi MDS menunjukkan kondisi atau status keberlanjutan perikanan tangkap mini purse seine (MPS) di keempat lokasi penelitian secara umum memiliki pola yang sama. Kisaran nilai dimensi ekologi antara $35,23-54,70 \%$ mencerminkan kondisi buruk hingga sedang. Secara relatif kondisi terburuk dijumpai di Kabupaten Lamongan serta terbaik dijumpai di Kabupaten Indramayu. Dimensi ekonomi dengan kisaran sempit antara $48,91 \%$ untuk Kabupaten Lamongan hingga $54,40 \%$ untuk Kabupaten Indramayu. Kisaran sempit ini menunjukkan hasil keuntungan yang diperoleh secara ekonomi relatif sama bagi nelayan MPS di keempat lokasi penelitian.

Kajian terhadap dimensi sosial perikanan tangkap MPS di keempat lokasi penelitian menunjukkan kisaran yang relatif lebih lebar dibandingkan kisaran pada dimensi ekonomi. Kisaran dimensi ini yaitu antara sedang $(56,45 \%)$ untuk Kota Pekalongan hingga cukup baik $(70,51$ dan $74,50 \%)$ untuk masing-masing di Kabupaten Lamongan dan Kabupaten Indramayu. Dari sisi teknologi secara keseluruhan menunjukkan perikanan tangkap nelayan MPS dilihat dari konsep pembangunan perikanan tangkap yang berkelanjutan cukup buruk. Buruknya kondisi dimensi ini ditampakkan dari kisaran nilai ordinasi MDS yang 
Tabel 4. Nilai analisis ordinasi MDS perikanan MPS Pantai Utara Jawa, 2003

Table 4. Score of ordination MDS analysis of MPS fishery of North Coast of Java, 2003

\begin{tabular}{lccccc}
\hline \multirow{2}{*}{$\begin{array}{c}\text { Perikanan/ } \\
\text { Fisheries }\end{array}$} & \multicolumn{5}{c}{ Dimensi/Dimensions } \\
\cline { 2 - 6 } & $\begin{array}{c}\text { Ekologi/ } \\
\text { Ecology }\end{array}$ & $\begin{array}{c}\text { Ekonomi/ } \\
\text { Economic }\end{array}$ & $\begin{array}{c}\text { Sosial/ } \\
\text { Social }\end{array}$ & $\begin{array}{c}\text { Teknologi/ } \\
\text { Technology }\end{array}$ & $\begin{array}{c}\text { Pengaturan/ } \\
\text { Governance }\end{array}$ \\
\hline Indramayu MPS & 49.70 & 54.40 & 74.50 & 39.51 & 64.81 \\
Pekalongan MPS & 54.70 & 51.23 & 56.45 & 37.03 & 64.22 \\
Tuban MPS & 49.70 & 50.05 & 62.49 & 38.05 & 63.61 \\
Lamongan MPS & $35.23^{*}$ & 48.91 & 70.51 & 38.86 & 64.32 \\
\hline Rata - rata & 47.33 & 51.15 & 65.99 & 38.36 & 64.24 \\
\hline
\end{tabular}

Sumber/Sources: Hasil olahan data, 2003/Processed data, 2003

Keterangan/Note: * Nilai 35,23 hanya digunakan sebagai perbandingan dikarenakan nilai total atribut "killer" lebih dari lima (5)/ The value of 35.23 in MPS lamongan fisheries only used as a compared value, since the total value of "killer" atributtes of it is more than five (5).

diperoleh, yaitu antara $37,03-39,51 \%$. Tingkat pengelolaan perikanan tangkap di Pantura Jawa untuk MPS di keempat lokasi penelitian berdasarkan pada nilai dimensi pengaturan (governance) kisarannya relatif sempit, yaitu antara $63,61-64,81 \%$. Hasil ini menunjukkan tingkat pengaturan berada pada level sedang dalam kondisi yang relatif sama.

Berdasarkan uraian kondisi kelima dimensi di keempat lokasi penelitian dan logika keterkaitan antar dimensi dapat ditarik suatu benang merah antara kondisi dan permasalahan yang timbul. Berdasarkan pada nilai dimensi teknologi, tampak bahwa teknologi yang digunakan oleh nelayan berupa penggunaan alat tangkap MPS termasuk kedalam alat tangkap yang ekstraktif. Sifat alat tangkap ini dapat dilihat diantaranya dari tidak adanya alat yang digunakan untuk dapat menyeleksi hasil tangkapan (selective gear) dan penggunaan FADS.

Kondisi teknologi ini secara tidak langsung dapat menjelaskan fenomena pada dimensi ekonomi. Penggunaan suatu teknologi alat tangkap ekstraktif dalam jangka pendek menguntungkan pengguna teknologi (nelayan MPS). Hal ini tampak dari keuntungan yang diperoleh nelayan MPS di lokasi penelitian sepanjang 5-10 tahun terakhir. Keuntungan hasil tangkapan ini kemudian menjadi dasar para nelayan berlomba menggunakan MPS, dimana fenomena penambahan pesat armada ini terjadi hingga akhir tahun 2000. Penambahan dalam jumlah besar juga didukung oleh tidak adanya pengaturan jumlah nelayan secara formal oleh pemerintah maupun pengaturan informal oleh masyarakat nelayan setempat dalam bentuk tradisi lokal/setempat sebagaimana ditunjukkan hasil verifikasi lapang atas atribut "equity in entry into fisheries" dan "limited entry" dalam dimensi pengaturan/governance.
Penambahan jumlah alat tangkap tanpa disesuaikan dengan kondisi alam pada akhirnya berakibat keuntungan ekonomi yang diperoleh "semu". Artinya total economic value dari kegiatan penangkapan ikan dengan MPS tanpa disadari bernilai negatif. Minusnya nilai total ekonomi ini dikarenakan jumlah biaya eksternal (externality cost) dalam bentuk penurunan kualitas lingkungan laut serta kuantitas sumberdaya perikanan tangkap di dalamnya, sesungguhnya secara ekonomis lebih besar daripada keuntungan ekonomi "riil" yang diperoleh nelayan MPS.

Hasil penelitian menunjukkan bahwa penambahan armada ini terus berlangsung dan tanpa disadari telah sampai pada kondisi di mana lingkungan tidak lagi dapat berfungsi dengan baik sebagai penyedia bahan baku kegiatan ekonomi yang ditimbulkan oleh aktivitas penangkapan. Di samping itu, tanpa disadari modal kegiatan semakin menipis karena dalam kegiatan penangkapan tidak ada perhitungan biaya untuk pembesaran ikan yang ditanggung oleh lingkungan. Di Kabupaten Indramayu dan Kota Pekalongan meskipun hasil tangkapan nelayan MPS masih menguntungkan namun cenderung semakin menurun. Para nelayan MPS di Kabupaten Tuban dan Lamongan bahkan tidak lagi memperoleh hasil yang menguntungkan dari usaha perikanan tangkap yang dijalaninya.

Ketidakmampuan kondisi lingkungan perairan (Laut Jawa) untuk mendukung keberlanjutan subsektor perikanan ditemukan di semua lokasi penelitian. Kondisi ini tercermin pada dimensi ekologi dan teknologi. Pada dimensi ekologi, atribut exploitation status dan range collapse menunjukkan buruk. Sementara dari dimensi teknologi tampak dari belum adanya upaya perbaikan seperti strategi peningkatan teknologi didalam penangkapan ikan target (selective 
gear) berakibat pada masih cukup banyaknya ikan non-target yang tertangkap.

Masih bertahannya usaha perikanan tangkap MPS hingga kini dikarenakan oleh dukungan dimensi sosial yang ditunjukkan oleh nilai dimensi yang relatif tinggi. Di Kabupaten Indramayu, kesulitan ekonomi akibat berkurangnya pendapatan nelayan MPS terutama diatasi dengan berjalannya fungsi KUD. Sementara di Kabupaten Lamongan dukungan dimensi sosial terwujud melalui jalinan "patron-klien" antara juragan kapal (laut atau darat) dengan bakul atau pemilik toko perbekalan. Juragan-juragan itu dapat meminjam biaya operasional kepada dua pihak tersebut dengan jaminan hasil tangkapan mereka. Sistem kelembagaan ekonomi ini menyebabkan banyak juragan kapal di Kabupaten Lamongan yang terlibat hutang. Besarnya hutang bahkan ada yang telah mencapai puluhan juta rupiah karena juragan tidak mampu mengembalikannya akibat hasil tangkapan yang tidak menguntungkan.

Kajian terhadap dimensi pengaturan menunjukkan meskipun pengaturan perikanan tangkap MPS relatif sudah cukup baik, namun masih perlu perbaikan. Perbaikan dari hasil analisis dimensi pengaturan terutama pada proses perumusan dan implementasi kebijakan.

Tabel 5. Atribut yang berpengaruh besar terhadap status keberlanjutan perikanan MPS di empat kabupaten Pantai Utara Jawa, 2003 (Hasil analisis leverage)

Table 5. Atributtes having a big influence to the sustainability status of MPS fisheries in four regencies of North Coast of Java, 2003 (Leverage analysis result)

\begin{tabular}{|c|c|c|c|c|}
\hline Dimensi/ & & Kabupaten/K & ta - Regencies & \\
\hline Dimensions & Indramayu & Pekalongan & Tuban & Lamongan \\
\hline Ekologi/ & Discarded by-catch & Discarded by-catch & Discarded by-catch & Range collapse \\
\hline Ecology & Exploitation status & Exploitation status & Range collapse & Size of fish caught \\
\hline & Range collapse & Primary production & Exploitation status & Discarded by-catch \\
\hline & Primary production & Rec. variability & Primary production & $\begin{array}{l}\text { Change in t. level } \\
\text { Catch b. maturity }\end{array}$ \\
\hline Ekonomi/ & Other income & Other income & Other income & Other income \\
\hline Economic & Sect. employment & Sect. employment & Sect. employment & Sect. employment \\
\hline & Fisheries in GDP & Fisheries in GDP & Fisheries in GDP & Fisheries in GDP \\
\hline & & & & Subsidy \\
\hline Sosial/ & Fisher influence & Conflict status & Fisher influence & Fisher influence \\
\hline Social & Env.knowledge & Fishing sector & Conflict status & Env. knowledge \\
\hline & Conflict status & Kin participation & Fishing income & Education level \\
\hline & Education level & $\begin{array}{l}\text { New entrans } \\
\text { i.fishery }\end{array}$ & Kin participation & Conflict status \\
\hline & Fishing income & & $\begin{array}{l}\text { Fishing sector } \\
\text { Education level }\end{array}$ & Kin participation \\
\hline Teknologi/ & Selective gear & Selective gear & Selective gear & Selective gear \\
\hline Technology & FADS & FADS & FADS & FADS \\
\hline & Gear & Gear & Gear & Gear \\
\hline & Pre-sale process. & Pre-sale process. & Pre-sale process. & Pre-sale process. \\
\hline & Vessel size & Vessel size & Vessel size & Vessel size \\
\hline Pengaturan/ & Limited entry & Limited entry & Limited entry & Limited entry \\
\hline Governance & Illegal fishing & Illegal fishing & Illegal fishing & Illegal fishing \\
\hline & Discards \& wastes & Discards \& wastes & Discards \& wastes & Discards \& wastes \\
\hline & Just management & Marketable right & Marketable right & Just management \\
\hline & $\begin{array}{l}\text { Marketable right } \\
\text { No of coastal reqlt. }\end{array}$ & $\begin{array}{l}\text { Just management } \\
\text { No of coastal realt }\end{array}$ & $\begin{array}{l}\text { Just management } \\
\text { No. of coastal reglt. }\end{array}$ & $\begin{array}{l}\text { Marketable right } \\
\text { No of coastal reglt. }\end{array}$ \\
\hline
\end{tabular}

Keterangan/Note: Atribut berpengaruh besar adalah atribut dengan nilai leverage di atas rata-rata seluruh atribut per dimensi; urutan atribut menunjukkan besarnya pengaruh di setiap dimensi/ The big effect attribute has a leverage value above the average for all attribute per dimension; attribute sequence show the level of influence in every dimension. 


\section{Faktor Berpengaruh Terhadap Keberlanjutan Perikanan MPS}

Hasil analisis Leverage, sebagai kelanjutan metode RAPFISH, menunjukkan atribut-atribut yang berpengaruh besar terhadap status keberlanjutan perikanan tangkap MPS pada setiap lokasi penelitian. Secara rinci hasil analisis Leverage ditampilkan pada Tabel 5.

Atribut-atribut yang berpengaruh di keempat lokasi penelitian secara umum menunjukkan kesamaan pola. Kesamaan pola dapat diartikan bahwa keempat lokasi penelitian cukup mewakili perkembangan perikanan tangkap MPS Pantai Utara Jawa.

Lebih lanjut, sejumlah atribut yang berpengaruh (Tabel 5) dipilih untuk mewakili indikator-indikator kinerja pembangunan berkelanjutan bagi perikanan tangkap MPS di Pantai Utara Jawa (Tabel 6). Mekanisme penyusunan indikator ditekankan pada batasan "kinerja", dimana didalam kinerja, terkandung tahapan input - proses - output. Oleh karena itu atribut-atribut berpengaruh yang digunakan sebagai

Tabel6. Implikasi kebijakan pembangunan berkelanjutan perikanan MPS di Pantai Utara Jawa, 2003

Table 6. The implication of sustainable development policy for MPS fisheries in North Coast of Java, 2003

$\begin{array}{ccc}\text { Tahapanl } & \text { Status/ } & \text { Kondisi/Status Pembangunan Berkelanjutan } \\ \text { Indikator Kinerjal } & \text { Status } & \text { Perikanan Tangkap (Rekomendasi)/ } \\ \begin{array}{c}\text { Stages/Performance } \\ \text { Indicators }\end{array} & & \begin{array}{c}\text { Recommendations for Sustainable Development } \\ \text { Conditions/Status of Capture Fisheries }\end{array}\end{array}$

A. INPUT I INPUT

Primary production

Environmental

knowledge

Education level

Selective gear

Just management

Illegal fishing

Limited entry

No. of coastal

regulation
$\mathrm{K}$ Tingkat kesuburan perairan yang baik/

Good level of temitorial water fertility

P Ada dan terpeliharanya budaya bahari masyarakat nelayan terutama yang terkait dengan kelestarian lingkungan dan sumberdaya perikanan tangkap/

Fishers society has a maritim culture, and it is exist and looked after, particularly which related to continuity of environment and capture fishery resources

$\mathrm{K} \quad$ Tingginya tingkat pendidikan nelayan dan keluarganya diseitai mudahnya akses untuk mendapatkan pelayanan di bidang pendidikan/

A good education for fishers and his family with an easily acsess to educational services.

$\mathrm{K}$ Tersedianya teknologi penangkapan yang selektif atau ramah lingkungan/ The available of environmental friendly or selective capture fishery technology

P Community Based Management (CBM) sebagai tipe pengelolaan lingkungan dan sumberdaya perikanan tangkap/ Community Based Management (CBM) is a type of capture fishery natural resources and environmental management

Tersedianya sarana dan prasarana dalam pengawasan kegiatan penangkapan yang ilegal/ The available of surveillance infrastructure of illegal fishing activities

$\mathrm{K} \quad$ Jumlah kapal yang beroperasi sesuai dengan potensi perikanan di wilayah perikanan yang dimiliki/ The balancing of operated ships with the potency of fishery resources in each fishery region.

$\mathrm{K}$ Tersedianya peraturan perundangan, baik secara kuantitas maupun kualitas, di bidang pengelolaan sumberdaya perikanan tangkap di laut/ The available of good regulation in the marine capture fishery management, either quantity and quality aspects 
Tabel 6. Implikasi kebijakan pembangunan berkelanjutan perikanan MPS di Pantai Utara Jawa, 2003 (lanjutan) Table 6. The implication of sustainable development policy for MPS fisheries in North Coast of Java, 2003 (continued)

\begin{tabular}{|c|c|c|}
\hline $\begin{array}{l}\text { Tahapan/ } \\
\text { Indikator Kine rja/ } \\
\text { Stages/Performance } \\
\text { Indocators }\end{array}$ & $\begin{array}{l}\text { Status } \\
\text { Status }\end{array}$ & $\begin{array}{l}\text { Kondisi/Status Pembangunan Berkelanjutan } \\
\text { Perikanan Tangkap (Rekomendasi) } I \\
\text { Recommendations for Sustainable Development } \\
\text { Conditions/Status of Capture Fisheries }\end{array}$ \\
\hline
\end{tabular}

\section{B. PROSES / PROCESSES}

\begin{tabular}{|c|c|c|}
\hline Market & $\mathrm{K}$ & $\begin{array}{l}\text { Akses pasar yang mudah serta adanya pengawasan terhadap harga } \\
\text { jual ikan di tingkat nelayan/ Easily access to fish market and the } \\
\text { existence of fish sell value surveillance in fisher level }\end{array}$ \\
\hline Other income & $\mathrm{K}$ & $\begin{array}{l}\text { Diversifikasi pendapatan keluarga nelayan (misal: banyaknya upaya } \\
\text { pengembangan agribisnis)/ Diversification of fisher household } \\
\text { income earnings of fisherman family (e.g. the number of } \\
\text { agribusiness development) }\end{array}$ \\
\hline Exploitation status & $\mathrm{K}$ & $\begin{array}{l}\text { Tingkat eksploitasi sesuai dengan MSY/ The exploitation level based } \\
\text { on MSY }\end{array}$ \\
\hline Conflict status & $P$ & $\begin{array}{l}\text { Pengaturan wilayah penangkapan dengan berdasarkan pada jenis } \\
\text { alat tangkap dan wilayah administrasi pemerintah/ The arrangement } \\
\text { of fishing ground based on type of capture technology and } \\
\text { governmental administration region }\end{array}$ \\
\hline Vessel size & K & $\begin{array}{l}\text { Pelayanan pemberian ijin usaha perikanan yang baik, sehingga } \\
\text { jumlah armada berikut ukurannya terdata dengan baik/ Giving a } \\
\text { fishing industry permit following by appropriate of ship number } \\
\text { administration }\end{array}$ \\
\hline Pre-sale process. & $\mathrm{K}$ & $\begin{array}{l}\text { Tingginya nilai tambah produk perikanan tangkap/ Highly added value } \\
\text { of capture fisheries products }\end{array}$ \\
\hline Fisher influence & K & $\begin{array}{l}\text { Masyarakat nelayan sangat berperan dalam pengambilan kebijakan } \\
\text { di bidang pengelolaan perikanan tangkap/ Fisher society play an } \\
\text { important role in the decision making of marine capture fishery } \\
\text { management }\end{array}$ \\
\hline Illegal fishing & K & $\begin{array}{l}\text { Pengawasan rutin terhadap kegiatan penangkapan ilegal/ The regular } \\
\text { surveillance of illegal fishing }\end{array}$ \\
\hline \multicolumn{3}{|c|}{ C. OUTPUT I OUTPUT } \\
\hline Primary production & $\mathrm{K}$ & $\begin{array}{l}\text { Tingkat kesuburan perairan yang baik/Good territorial marine water } \\
\text { fertilities }\end{array}$ \\
\hline Sect. employment & $\mathrm{K}$ & Penyerapan tenaga kerja yang tinggi//Highly absorption of labor force \\
\hline Fisheries in GDP & $\mathrm{K}$ & $\begin{array}{l}\text { Terintegrasinya industri perikanan dengan industri lain/Marine } \\
\text { capture fishery industries are integrated with other related industry }\end{array}$ \\
\hline Fishing income & $\mathrm{K}$ & Tingginya tingkat pendapatan nelayan/Highly fisher income \\
\hline Discards \& wastes & $\mathrm{K}$ & $\begin{array}{l}\text { Peningkatan selektifitas teknologi penangkapan ikan dan monitoring } \\
\text { ikan by-catch/The improvement of selective fish capture technology } \\
\text { and monitoring of fish by-catch }\end{array}$ \\
\hline Marketable right & $\mathrm{K}$ & $\begin{array}{l}\text { Penciptaan regulasi yang dapat memperjual-belikan ijin pengusahaan } \\
\text { perikanan tangkap laut (jangka panjang)/Conduct the commercial } \\
\text { capture fishery permit (for long term policy) }\end{array}$ \\
\hline
\end{tabular}

Keterangan/Notes: $\mathrm{P}=$ Potensi/Potency; $\mathrm{K}=$ Kendala/permasalahan $/$ Problem 
indikator dibagi kedalam indikator kinerja tahapan input, proses dan output. Mekanisme pembagian indikator ini bertujuan agar pihak pengambil kebijakan pengelolaan perikanan tangkap tidak hanya terfokus pada indikator tahapan output sebagaimana banyak terjadi saat ini, tetapi juga memberikan perhatian pula pada indikator-indikator kinerja untuk tahapan input dan proses.

Berdasarkan kondisi yang tergambar pada saat ini, seluruh atribut yang berpengaruh dibagi menjadi dua kelompok. Kelompok pertama adalah atribut dalam posisi sebagai potensi (bersifat positif) terhadap kelestarian perikanan tangkap pada suatu wilayah. Kelompok kedua adalah atribut atribut dalam posisi sebagai kendala (bersifat negatif) terhadap keberlanjutan perikanan tangkap di suatu wilayah.

\section{KESIMPULAN DAN SARAN}

Hasil penelitian menunjukkan bahwa metode RAPFISH cukup mampu menggambarkan dengan baik status keberlanjutan perikanan MPS di Kabupaten Indramayu, Kota Pekalongan, Kabupaten Tuban dan Lamongan. Hasil analisis ordinasi MDS yang menunjukkan status keberlanjutan perikanan MPS di keempat lokasi relatif sama. Hasil analisis leverage menunjukkan status keberlanjutan perikanan tangkap juga dipengaruhi oleh atribut-atribut yang secara umum juga sama. Berdasarkan sifat atribut-atribut tersebut tampak bahwa pada saat ini lebih banyak kendala atau permasalahan dibandingkan potensi pada perikanan tangkap MPS.

Implikasi kebijakan yang secara umum dapat dirumuskan dari hasil penelitian ini dengan mengetahui pengaruh dari atribut-atribut tersebut (positif atau negatif) adalah berupa rekomendasi penanganan berbagai faktor yang memiliki potensi untuk mengancam keberlanjutan perikanan tangkap MPS di pantai utara jawa saat ini (berdasarkan atributatribut "kendala"). Rekomendasi lainnya adalah Pengembangan dan peningkatan kinerja berbagai faktor yang mendukung keberlanjutan perikanan tangkap MPS di pantai utara jawa (berdasarkan atributatribut "potensi").

Status keberlanjutan yang diperoleh dari hasil analisis pada penelitian ini juga menunjukkan perlunya keseriusan serta tindakan yang cepat didalam perumusan dan pengambilan kebijakan sebagaimana rekomendasi yang diberikan.

\section{DAFTAR PUSTAKA}

Alder, J., Zeller, D., Pitcher, T. and Sumalia, R. 2002. A method for evaluating marine protected area management. Coastal Management Journal 30 (2): 121 131.

Bossel, H. 1999. Indicators for Sustainable Development: Theory, Method, Applications. The International Institute for Sustainable Development. Winnipeg Manitoba. 124 pp.

Dahuri, R., Rais, J., Ginting, S.P., Sitepu, M.J. 1996. Pengelolaan Sumberdaya Wilayah Pesisir dan Lautan Secara Terpadu. Pradnya Paramita. Jakarta. $305 \mathrm{pp}$.

Durand, J.R., Petit, D., Potier, M., Roch, J. and Widodo, J. 1996. Multidiciplinary Studies for Fishery Management, Case Study: Java Sea Pelagic Fisheries. In Java Sea Pelagic Fishery Assessment Project. Collected Reprint on The Pelfish Communications Given to The Fourth Asian Fisheries Forum, 16-20 October, Beijing, Document 25: 61-68.

Fauzi, A. dan Anna, S. 2002. Evaluasi Satus Keberlanjutan Pembangunan Perikanan: Aplikasi Pendekatan RAPFISH (Studi Kasus Perairan Pesisir DKI Jakarta). Jurnal Pesisir dan Lautan, 4(3): 44-55.

Garcia, S.M., Staples, D.J. and Chesson. 2000. The FAO Guidelines for The Development and Use of Indicators for Sustainable Development of Marine Capture Fisheries and An Australian Example of Their Application. Ocean and Coastal Management 43 (2000): 537-556.

Kavanagh, P. 2001. RAPFISH Software Description (for Microsoft Excel): Rapid Appraisal for Fisheries (RAPFISH) Project. Fisheries Center University of British Columbia. Vancouver. $36 \mathrm{pp}$

Pitcher, T.J. and Preikshot, D. 2001. RAPFISH: A Rapid Appraisal Technique to Evaluate the Sustainability Status of Fisheries. Fisheries Research 49(3): 255270. Fisheries Center University of British Columbia. Vancouver.

Randall, A. 1994. Resource Economics: An Economic Approach to Natural Resource and Environmental Policy. Grid Publishing, Inc. Ohio. 415 pp.

Taryono. 2003. Analisis Ekonomi Kelestarian Sumberdaya Perikanan Laut Pantai Utara Jawa. Thesis. (Tidak dipublikasikan). Program Pascasarjana Institut Pertanian Bogor. Bogor. 192 pp. 